\title{
Sodium Channels in Transient Retinal Bipolar Cells Enhance Visual Responses in Ganglion Cells
}

\author{
Tomomi Ichinose, Colleen R. Shields, and Peter D. Lukasiewicz \\ Department of Ophthalmology and Visual Sciences and Department of Anatomy and Neurobiology, Washington University School of Medicine, St. Louis, \\ Missouri 63110
}

\begin{abstract}
Retinal bipolar cells are slow potential neurons that respond to photoreceptor inputs with graded potentials and do not fire action potentials. We found that transient $\mathrm{ON}$ bipolar cells recorded in retinal slices possess voltage-gated sodium channels located on either their dendrites or somas. The sodium currents in these neurons did not generate spikes but enhanced voltage responses evoked by visual stimulation, which selectively boosted transmission to transient ganglion cells. In contrast, sodium currents were not found in sustained ON bipolar cells, and light responses in sustained bipolar cells and ganglion cells were not affected by TTX. The presence of sodium channels in transient $\mathrm{ON}$ bipolar cells contributed to the separation of transient and sustained signals by selectively enhancing the responses of $\mathrm{ON}$ transient ganglion cells to light. Our results suggest that bipolar cell sodium channels augment transient signals and contribute to the temporal segregation of visual information.
\end{abstract}

Key words: retina; patch clamp; sodium channel; EPSC; EPSP; retinal ganglion cell; glutamate receptor

\section{Introduction}

Voltage-gated sodium channels on the soma and the axon of neurons propagate action potentials to the axon terminal, giving rise to transmitter release. Sodium channels are also found on the dendrites or somas of many CNS neurons where they boost the amplitude of excitatory synaptic inputs (Stuart and Sakmann, 1994; Schwindt and Crill, 1995; Stuart and Sakmann, 1995; Gonzalez-Burgos and Barrionuevo, 2001).

Retinal bipolar cells, in contrast to most CNS neurons, do not fire action potentials (Werblin and Dowling, 1969). Instead, electrical signals propagate passively along bipolar cell axons. However, recent studies indicate that voltage-gated sodium channels are present on the dendrites or somas of subsets of dissociated rat and goldfish bipolar cells (Pan and $\mathrm{Hu}, 2000$; Zenisek et al., 2001). These sodium channels may act similarly to those found on dendrites of other CNS neurons to enhance excitatory synaptic responses to light.

Because the contributions of voltage-gated sodium channels on bipolar cells to visual signaling are unknown, we investigated whether these channels affected light-evoked inputs and outputs of bipolar cells in the salamander retina. Blocking sodium channels with TTX or intracellular lidocaine $N$-ethyl bromide quater-

Received Sept. 13, 2004; revised Jan. 10, 2005; accepted Jan. 10, 2005.

This work was supported by National Institutes of Health Grants EY08922 and EY02687, the Research to Prevent Blindness, and the M. Bauer Foundation. We thank members of the Lukasiewicz laboratory for helpful discussion and comments on this manuscript.

Correspondence should be addressed to Peter D. Lukasiewicz, Department of Ophthalmology, Campus Box 8096 Washington University School of Medicine, 660 South Euclid Avenue, St. Louis, M0 63110. E-mail: Lukasiewicz@vision.wustl.edu.

C. R. Shields's present address: Retinal Signal Processing Group, Netherlands Ophthalmic Research Institute, Meibergdreef 47, 1105 BA Amsterdam, The Netherlands.

DOI:10.1523/JNEUROSCI.5208-04.2005

Copyright $\odot 2005$ Society for Neuroscience $\quad$ 0270-6474/05/251856-10\$15.00/0 nary salt (QX-314) reduced the amplitude of light-evoked EPSPs (L-EPSPs) in transient ON bipolar cells, suggesting that sodium channels selectively boost excitatory synaptic inputs in specific bipolar cell signaling pathways. Enhanced bipolar cell L-EPSPs affected retinal processing by augmenting the output of the retina. We found that blocking bipolar cell sodium currents with TTX selectively reduced light-evoked excitatory signaling to a class of ON-OFF ganglion cells of which dendrites costratified in the mid-inner plexiform layer (IPL) with transient ON bipolar cell axon terminals. We have shown for the first time that voltagegated sodium channels enhance visual inputs to a class of ON bipolar cells, augmenting signaling to transient ganglion cells and enhancing their responses to light.

\section{Materials and Methods}

Retinal slice preparation. Larval tiger salamanders were obtained from Charles Sullivan (Nashville, TN) and were kept in aquaria at $5^{\circ} \mathrm{C}$ on a $12 \mathrm{~h}$ light/dark cycle. Salamanders were dark adapted for at least $1 \mathrm{~h}$ before dissections. The experimental protocol was approved by the Washington University Institutional Animal Care and Use Committee. Dissection and recording procedures were performed under infrared (IR) illumination using IR viewers. In a few experiments, dissections were performed under dim red illumination. Similar results were obtained for the two dissection conditions. Retinal slices were prepared as described by Lukasiewicz et al. (1994). The retina was removed from the eye, placed on Millipore filters (HAWP01300; Millipore, Bedford, MA) vitreal side down, and sliced at $250 \mu \mathrm{m}$ intervals. Individual slices were transferred to a recording chamber and viewed through an upright, fixed-stage microscope (Eclipse E-600-FN; Nikon, Tokyo, Japan) equipped with a $40 \times$ water-immersion lens and Hoffman modulation contrast optics (Modulation Contrast, Gleenvale, NY). Using a gravity-fed system, the preparation was continually superfused at $2 \mathrm{ml} / \mathrm{min}$ with a Ringer's solution containing the following (in mM): $112 \mathrm{NaCl}, 2 \mathrm{KCl}, 2 \mathrm{CaCl}_{2}, 1 \mathrm{MgCl}_{2}, 5$ glucose, and 5 HEPES, adjusted to $\mathrm{pH} 7.8$ with $\mathrm{NaOH}$. For voltage-gated sodium current recordings from bipolar cells, we used a Ringer's solution 
containing the following (in mM): $100 \mathrm{NaCl}, 2 \mathrm{KCl}, 10 \mathrm{TEA}, 3 \mathrm{MgCl}_{2}, 5$ glucose, 5 HEPES, and $2 \mathrm{CoCl}_{2}$. In some experiments, choline chloride was substituted for $\mathrm{NaCl}$ to reduce voltage-gated sodium currents in bipolar cells.

Whole-cell recording. Electrodes were pulled from borosilicate glass (IB150F-4; World Precision Instruments, Sarasota, FL) with a P-97 Flaming/Brown micropipette puller (Sutter Instruments, Novato, CA). Whole-cell recordings were made from ganglion cells by using $5 \mathrm{M} \Omega$ pipettes filled with a solution containing (in $\mathrm{mM}$ ) $95.25 \mathrm{Cs}$-gluconate, 8 TEA-Cl, $0.4 \mathrm{MgCl}_{2}, 1 \mathrm{EGTA}$, and $10 \mathrm{Na}$-HEPES, adjusted to $\mathrm{pH} 7.5$ with $\mathrm{HCl}$, or from bipolar cells with electrodes containing (in $\mathrm{mM}$ ) 85 K-gluconate, $10 \mathrm{KCl}, 10 \mathrm{HEPES}, 10 \mathrm{BAPTA}, 4 \mathrm{Mg}$-ATP, $1 \mathrm{Na}-\mathrm{GTP}$, adjusted to $\mathrm{pH} 7.4$ with $\mathrm{KOH}$. For voltage-gated current recordings from bipolar cells, the electrode solution contained the following (in $\mathrm{mM}$ ): 85 K-gluconate, 10 TEA, 10 HEPES, 10 BAPTA, 4 Mg-ATP, and 1 Na-GTP. Lucifer yellow (0.05\%; Sigma-Aldrich, Milwaukee, WI) was included in the pipette solution to identify cell morphologies. Membrane potentials were corrected for junction potentials $(-14.9 \mathrm{mV}$ for ganglion cell solution; $-19 \mathrm{mV}$ for bipolar cell solution).

The voltage-clamp or current-clamp recordings were made with an Axopatch 200A Patch Clamp Amplifier (Axon Instruments, Foster City, $\mathrm{CA}$ ). Data were digitized and stored with a personal computer using TL-1 data acquisition system (Axon Instruments). Patchit software (White Perch Software, Somerville, MA) was used to generate voltage-command outputs, acquire data, control the light stimuli, and operate the drug perfusion system. Data were filtered at $1 \mathrm{kHz}$ with a four-pole Bessel filter and were sampled at $1-10 \mathrm{kHz}$.

Drugs. A computer-controlled superfusion system was used to apply drug-containing Ringer's solutions to the recording chamber. For all experiments, glycine receptors were blocked with strychnine $(5 \mu \mathrm{M})$. D(-)-2-amino-5-phosphonopentanoic acid (D-AP-5) and L(+)-2amino-4-phosphonobutyric acid (L-AP-4) were obtained from Precision Biochemicals (Vancouver, Canada). All other chemicals were obtained from Sigma (St. Louis, MO).

Light stimulation. The bipolar or ganglion cell-receptive field center was activated by a small spot of red light (180 $\mu \mathrm{m}$ diameter) from a tungsten-halogen light source (20 W; Ealing Electro-Optics, Holliston, MA) using a red interference filter $\left(\lambda_{\max }=633 \mathrm{~nm}\right)$. The light stimulus was projected through the objective via a light pipe attached to the microscope camera port and was presented every $30-60$ s. The intensity of the unattenuated light stimulus in the plane of the preparation was equivalent to $5.0 \times 10^{8}$ photons $/ \mu \mathrm{m}^{2} / \mathrm{s}$ of a monochromatic light of 700 $\mathrm{nm}$. Light intensity was varied with neutral density filters. Light intensityresponse relationships were obtained by plotting ON-EPSC amplitude as a function of the light intensity. For all other experiments, light intensity was selected to produce half-maximal responses.

Cell morphology. The morphological classes of ganglion cells and bipolar cells were determined by labeling the cells with Lucifer yellow $(0.01 \%)$, included in the recording electrode. Cell morphology was documented by photographing and drawing the filled neuron at the conclusion of each experiment. The arborization of bipolar cell axonal processes or ganglion cell dendrites was characterized by their stratification depths in the IPL (Nelson et al., 1978; Wu et al., 2000). The ramification of processes were analyzed and defined as "outermost IPL" when a process ramified at $0-20 \%$ of IPL, as "mid-IPL" when ramified at $20-80 \%$ of IPL, or as "innermost IPL" when ramified at $80-100 \%$ of IPL. The stratification pattern of each cell is summarized in Figure 6.

Voltage-gated bipolar cell currents. To activate voltage-gated currents, bipolar cells were voltage clamped at $-60 \mathrm{mV}$ and then prepulsed to either -50 or $-80 \mathrm{mV}$ for $500 \mathrm{~ms}$, followed by a test pulse to $-10 \mathrm{mV}$ for $50 \mathrm{~ms}$ every $15 \mathrm{~s}$. The TTX-sensitive, inward current was obtained by subtracting the averaged TTX current from the averaged control current. To determine the activation and inactivation properties of the sodium current, we varied either test pulse or prepulse for the activation and inactivation experiments, respectively, as detailed in the Results and in Figure $3 f$.

Analysis. For all of the experiments, peak amplitude was measured using Tack analysis software (White Perch Software). The ganglion cell light intensity-response curve was fitted with the Hill equation: $Y=$ a

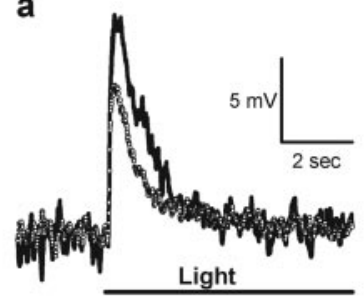

b

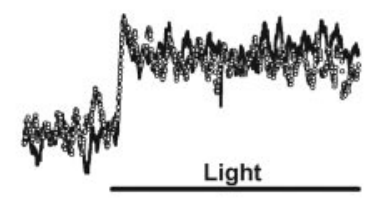

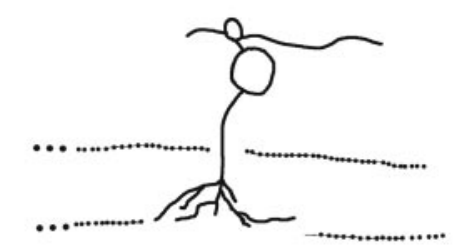
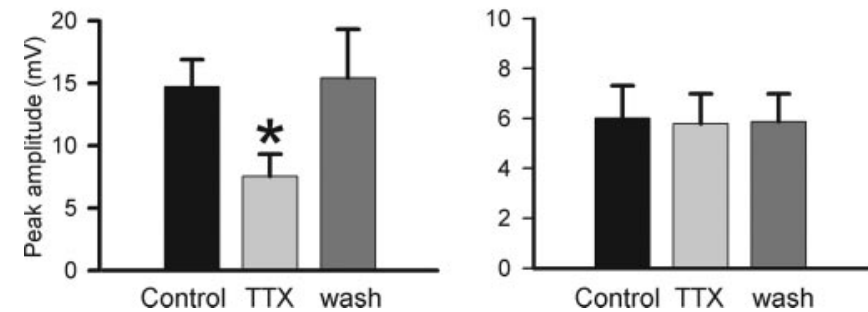

Figure 1. TTX reduced light-evoked responses in transient, but not sustained, ON bipolar cells. $\boldsymbol{a}$, Transient EPSPs (solid trace) were evoked in response to light stimulation in 0N bipolar cells of which axon terminals ramified the mid-IPL (top and middle). Strychnine (5 $\mu \mathrm{M})$, bicuculline $(200 \mu \mathrm{m})$, I4AA $(20 \mu \mathrm{m})$, picrotoxin $(200 \mu \mathrm{m})$, CNQX (30 $\mu \mathrm{m})$, and D-AP-5 (50 $\mu \mathrm{m})$ were present in the bath to block network effects and isolate photoreceptor inputs. TTX $(0.5 \mu \mathrm{M})$ reduced the EPSPs (dotted trace). Summary graph shows that TTX reduced the peak EPSP amplitude in transient ON bipolar cells (control, 14.7 $\pm 2.2 \mathrm{mV} ; \mathrm{TTX}, 7.55 \pm 1.8 \mathrm{mV} ;{ }^{*} p<0.01$; $n=7$; bottom). $\boldsymbol{b}$, Sustained EPSPs (solid trace) were evoked in response to light stimulation in ON bipolar cells of which axon terminals ramified the innermost IPL (top and middle). TTX did not affect the EPSPs (dotted trace). Summary graph shows that TTX did not change the EPSP amplitude in sustained ON bipolar cells (control, $6.01 \pm 1.3 \mathrm{mV} ; \operatorname{TTX}, 5.78 \pm 1.2 \mathrm{mV} ; p=0.12$; $n=7$; bottom). The duration of the light stimulus is indicated by a solid line below the response traces. Scale bar: $\boldsymbol{a}, \boldsymbol{b}, 10 \mu \mathrm{m}$ (middle).

$a x^{\mathrm{b}} /\left(L_{50} \mathrm{~b}+x^{\mathrm{b}}\right)$, where $a$ is the maximum response, $b$ is the slope factor, and $L_{50}$ is the light intensity at the half-maximum response. For Figure $7 a$, the control light-response curve was normalized to the maximum amplitude and $L_{50}$ in each cell. For Figure $7 b$, curves were normalized to the average maximum and $L_{50}$ values of TTX-sensitive ganglion cells. The dynamic range $(w)$ was defined by the equation: $w=2^{*}\left(\log L_{90}-\log \right.$ $L_{50}$ ), where $L_{90}$ is the light intensity at $90 \%$ of maximum response (Euler and Masland, 2000). The peak/sustained index of bipolar cell light responses was calculated as follows: index $=$ (peak amplitude/plateau amplitude). The paired $t$ test was used to determine whether a response was significantly different in the presence or absence of TTX. In the text, values are presented as mean $\pm \mathrm{SE}$, and differences were considered significant if $p<0.05$.

\section{Results}

\section{TTX reduced light-evoked EPSPs in transient ON} bipolar cells

Recent studies indicate that voltage-gated sodium channels are present on the dendrites or somas of subsets of dissociated rat and goldfish bipolar cells (Pan and Hu, 2000; Zenisek et al., 2001); however, it is not known whether they contribute to visual signaling in bipolar cells. To determine whether voltage-gated sodium channels boost their light-evoked voltage responses, we recorded L-EPSPs from ON bipolar cells in the absence or pres- 
ence of TTX $(0.5 \mu \mathrm{M})$. Figure 1 shows the response of a transient (Fig. 1 $a$, top) and a sustained (Fig. 1b, top) ON bipolar cell to illumination of its receptive field center. We isolated the metabotropic glutamate receptor 6 (mGluR6)-mediated transmission between photoreceptors and $\mathrm{ON}$ bipolar cells by including glycine, $\mathrm{GABA}_{\mathrm{A}}$, $\mathrm{GABA}_{\mathrm{C}}$, and ionotropic glutamate receptor blockers in the bath. TTX reduced the L-EPSPs of transient ON bipolar cells (Fig. $1 a$, top and bottom), suggesting that voltage-gated sodium channels enhanced light responses in these bipolar cells. This class of ON bipolar cells was characterized by axon terminals that ramified in the mid-IPL (Fig. 1a, middle). In two axotomized transient ON bipolar cells, TTX reduced the light response, suggesting that the sodium channels were located on their dendrites or soma. In contrast, TTX did not affect the L-EPSPs of sustained ON bipolar cells (Fig. 1b, top and bottom). The morphology of sustained ON bipolar cells was distinct from the transiently responding cells, their axon terminals ramified in the innermost sublaminas of the IPL (Fig. $1 b$, middle).

\section{TTX did not reduce photoreceptor input to bipolar cells}

The site of TTX action could be either at the bipolar cell itself or at the photoreceptors that provide bipolar cell input. The different effects of TTX on transient versus sustained ON bipolar cells suggested that TTX did not act at photoreceptors, because they presumably provide inputs to both types of bipolar cells. To determine whether TTX affected photoreceptor output, we assessed photoreceptor inputs to $\mathrm{ON}$ bipolar cells by voltage clamping $\mathrm{ON}$ bipolar cells to $-70 \mathrm{mV}$ to prevent the activation of sodium channels (Pan and Hu, 2000; Zenisek et al., 2001). The photoreceptor-mediated L-EPSCs recorded from ON bipolar cells were isolated by including $\mathrm{GABA}_{\mathrm{A}}, \mathrm{GABA}_{\mathrm{C}}$, glycine, and ionotropic glutamate receptor blockers in the bath. In agreement with our previous results (Shields and Lukasiewicz, 2003), TTX did not affect L-EPSCs recorded from ON bipolar cells (Fig. 2a). Because TTX did not alter the light-evoked input from photoreceptors but did decrease the light-evoked voltage responses, it is likely that TTX acted on the bipolar cell directly and not presynaptically at either photoreceptors or horizontal cells.

We showed, using another approach, that the photoreceptor input was not altered by TTX. If the voltage-gated sodium channels in bipolar cells enhanced their light responses, the enhancement should not be observed after their sodium channels were inactivated by depolarizing the bipolar cell to positive membrane potentials. In contrast, if TTX acted on photoreceptors, L-EPSPs should be reduced at all membrane potentials. We recorded lightevoked EPSPs from transient ON bipolar cells, of which axon terminals ramified in the mid-IPL after they were depolarized to $30 \mathrm{mV}$ with positive currents. In five of seven bipolar cells, the L-EPSPs reversed polarity when positive currents of 100-250 pA were injected (Fig. 2b, thick line, top). TTX did not affect the L-EPSPs at this membrane potential (Fig. $2 b$, small circles, top), indicating that voltage-gated sodium channels in bipolar cells, and not photoreceptors, enhanced the L-EPSPs in transient ON bipolar cells. b EPSPs

C EPSPS
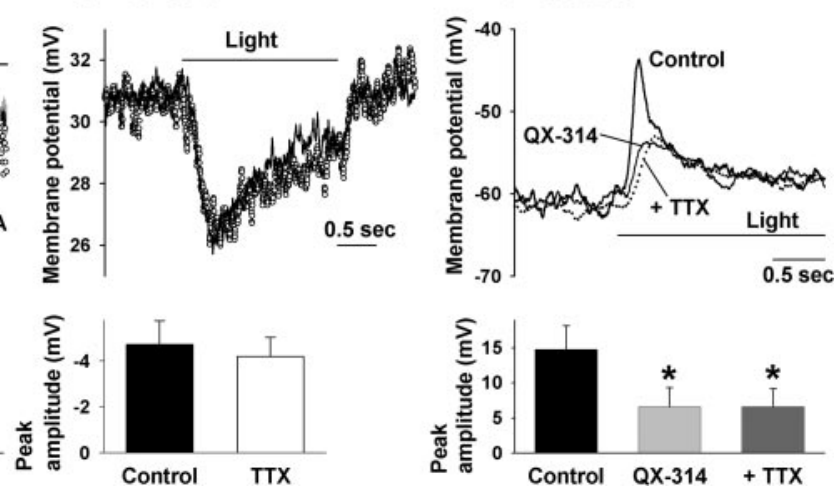

Figure 2. Bipolar cell light responses were enhanced by intrinsic sodium channels. $\boldsymbol{a}, \mathrm{L}$-EPSCs recorded at $-70 \mathrm{mV}$ in a transient $0 \mathrm{~N}$ bipolar cell (solid trace, top). Photoreceptor inputs were pharmacologically isolated, as detailed in Figure 1. TTX (0.5 (QX-314, top). The subsequent application of TTX did not affectthe EPSPs ( $+\pi X$, top). The bargraph summarizes the data (control, $14.8 \pm$ $3.4 \mathrm{mV}, Q X-314,6.61 \pm 2.7 \mathrm{mV},{ }^{*} p<0.05$ vs control; $+T \mathrm{TX}, 6.59 \pm 2.6 \mathrm{mV},{ }^{*} p<0.05$ vs control, $p=0.48$ vs $Q X-314 ; n=6 ;$ bottom). The duration of the light stimulus is indicated by the solid line above $(\boldsymbol{a}, \boldsymbol{b})$ or below $(\boldsymbol{c})$ the response traces.

\section{QX-314 occluded the TTX reduction of transient ON bipolar cell L-EPSPs}

To confirm that the site of action of the TTX reduction of L-EPSPs was at the transient ON bipolar cells, we tried to occlude the TTX effect by including QX-314 (10 mM) in the recording pipette. For the first few minutes after achieving the whole-cell recording configuration, the amplitudes of L-EPSPs recorded with the QX-314 pipettes were similar to control L-EPSPs (compare Fig. $2 c$, control, $p=0.18$, with Fig. $1 a$, control). After QX314 diffused throughout the cell and the responses stabilized (14 $\pm 2 \mathrm{~min}$ ), the average amplitude of the L-EPSPs was decreased by half (Fig. 2c, QX-314). The subsequent application of TTX did not affect the L-EPSPs (Fig. $2 c$, +TTX). In contrast, neither QX-314 nor TTX affected the L-EPSPs in sustained bipolar cells, confirming that voltage-gated sodium channels were present in transient $\mathrm{ON}$ bipolar cells.

\section{Sodium channel blockade reduced the peak-to-sustained L-EPSP ratio}

Sodium channel blockers (TTX and QX-314) and sodium channel inactivation at positive potentials not only reduced the peak amplitude of L-EPSPs in transient ON bipolar cells but also reduced the peak-to-sustained index (see Materials and Methods). If the peak response amplitude is equal to the sustained response amplitude, the index is 1.0. The index was reduced after sodium channels were inactivated by depolarization. In four of five transient $\mathrm{ON}$ bipolar cells, the index measured at the resting potential $-54 \pm 1.4 \mathrm{mV}(7.89 \pm 5.6)$ was reduced after the cells were depolarized to $+30 \mathrm{mV}(2.06 \pm 0.3 ; p<0.001 ; n=4)$. The fifth bipolar cell had axon terminals that ramified in the mid-IPL, but its index was low at both negative and positive potentials (1.7 vs 2.4). Consistent with the notion that sodium channels increase the peak to sustained index, sodium channel blockers reduced the index measured in transient $\mathrm{ON}$ bipolar cells from $6.81 \pm 1.5$ to $4.20 \pm 0.8(p<0.05 ; n=19)$. In contrast, the index measured in sustained bipolar cells was not affected by sodium channel blockers $(2.17 \pm 0.5$ to $2.31 \pm 0.4 ; p=0.16 ; n=5)$. These results 
a

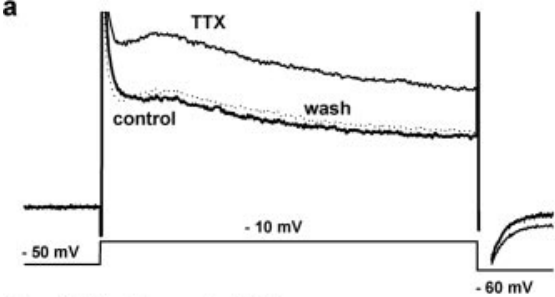

b Subtraction control-TTX

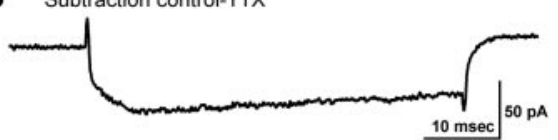

c

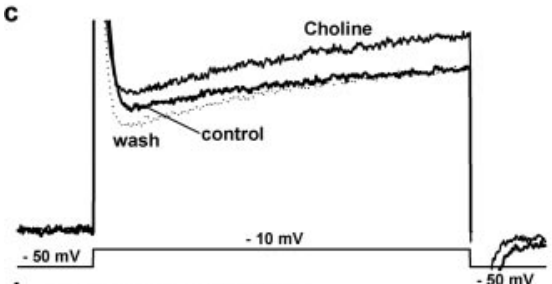

d Subtraction control-choline
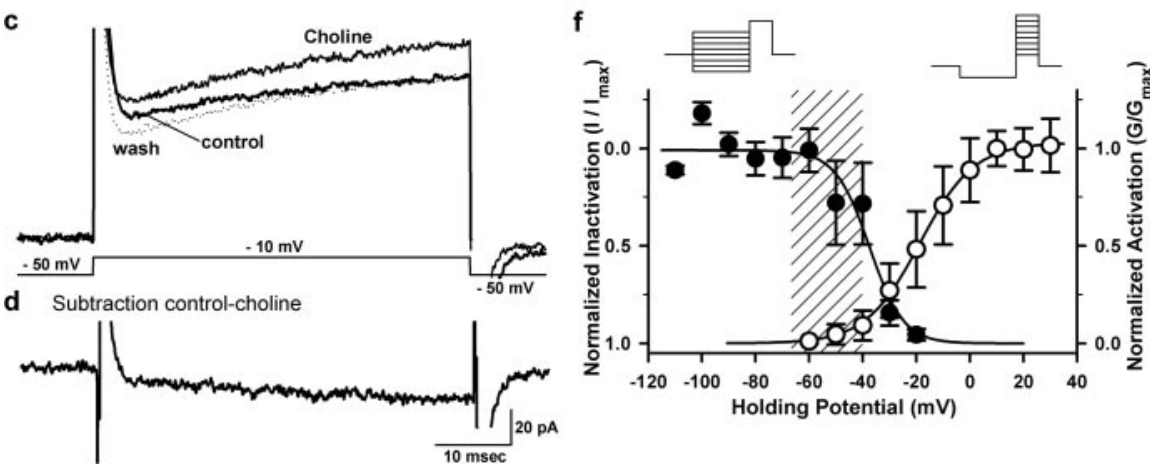

Figure 3. Voltage-gated sodium currents were recorded in transient $\mathrm{ON}$ bipolar cells. $\boldsymbol{a}$, Whole-cell membrane currents were recorded from an $0 \mathrm{~N}$ bipolar cell of which axon terminals ramified the mid-IPL in response to a voltage-clamp pulse from -50 to $-10 \mathrm{mV}$ (control). The calcium current was blocked with cobalt $(2 \mathrm{~mm})$, and potassium current was reduced by TEA included in both extracellular and intracellular solutions (see Materials and Methods). The major synaptic inputs to bipolar cells were blocked by including strychnine $(5 \mu \mathrm{M})$, bicuculline $(200 \mu \mathrm{M})$, I4AA $(20 \mu \mathrm{M})$, picrotoxin $(200 \mu \mathrm{M})$, CNQX $(30 \mu \mathrm{M}), \mathrm{D}-\mathrm{AP}-5(50 \mu \mathrm{M})$, and L-AP-4 (2 $\mu \mathrm{M})$. TTX ( $0.5 \mu \mathrm{m})$ shifted the current outward (TTX), and its effect reversed after wash out (wash). $\boldsymbol{b}$, The voltage-gated inward current was revealed when the current trace in the presence of TTX was subtracted from the current trace in control solution. $\boldsymbol{c}$, Whole-cell membrane currents were recorded as in $\boldsymbol{a}$. When extracellular sodium was replaced with choline, the current shifted outward (choline) and was reversed after wash out (wash). $\boldsymbol{d}$, An inward current was unmasked when the current in choline was subtracted from the current in control solution, indicating that the inward current was the voltage-gated sodium current. $\boldsymbol{e}$, Inward currents evoked by a series of positive $10 \mathrm{mV}$ voltage steps from $-80 \mathrm{mV}$. The currents represent the mean currents from five transient $\mathrm{ON}$ bipolar cells. $\boldsymbol{f}$, Activation and inactivation curves constructed for sodium channels on transient bipolar cells. Inactivation was determined by measuring currents in response to test pulses to $-10 \mathrm{mV}$, preceded by voltage prepulses from -120 to $-20 \mathrm{mV}$ for $500 \mathrm{~ms}$. The peak inward current was normalized by dividing by the maximal current (closed circles; $n=5$ ). Activation was determined by measuring currents in response to test pulses from -60 to $+40 \mathrm{mV}$, preceded by prepulse to $-80 \mathrm{mV}$ for $500 \mathrm{~ms}$. Currents recorded in TTX were then subtracted from control currents. Conductance $(g)$ was calculated by dividing the current by its driving force, using the following equation: $g=I /\left(V-E_{\mathrm{Na}}\right)$. The calculated $E_{\mathrm{Na}}$ was $+116 \mathrm{mV}$. The conductance was normalized by dividing each value by the maximum conductance (open circles; $n=4$ ). The solid lines through the data points were the best fit to the data of the Boltzmann equation as follows: $I=I_{\max } /\left(1+\exp \left[\left(V-V_{\mathrm{h}}\right) / k\right]\right)$ for inactivation; and $G=G_{\max } /\left(1+\exp \left[\left(V-V_{\mathrm{h}}\right) / k\right]\right)$ for activation. $V_{\mathrm{h}}$ is the half-inactivation voltage $(-37.5 \mathrm{mV})$ or half-activation voltage $(-18.7 \mathrm{mV})$, and $k$ is the slope factor. The range of resting membrane potentials of bipolar cells is shown by the hatching.

suggest that sodium channels enhance and shape light responses in transient, but not sustained, ON bipolar cells.

\section{Voltage-gated sodium currents were present in transient $\mathrm{ON}$ bipolar cells}

We directly measured whether voltage-gated sodium currents were present only in a subset of ON bipolar cells by stepping the membrane potential from -50 to $-10 \mathrm{mV}$ in either the presence or absence of TTX under experimental conditions similar to those for the recording of light-evoked voltage responses (Fig. $3 a$ ). The major synaptic inputs to bipolar cells were blocked by including glycine, $\mathrm{GABA}_{\mathrm{A}}, \mathrm{GABA}_{\mathrm{C}}$, ionotropic glutamate receptor antagonists, and a metabotropic glutamate receptor agonist, $\mathrm{AP}-4$, in the bath. We also blocked voltage-gated calcium currents in bipolar cells by replacing bath calcium with cobalt and reduced potassium currents by including TEA in the bath and electrode solutions. In seven ON bipolar cells, TTX reduced an inward current, shifting the currents outward for steps from -50 to $-10 \mathrm{mV}$. The axon terminals of six of seven ON bipolar cells ramified in the mid-IPL. The seventh bipolar cell was axotomized. Figure $3 b$ shows the TTXsensitive inward current obtained by subtracting the current trace measured in the presence of TTX from the control current trace. The maximum amplitude of the inward current was $-96.7 \pm 12 \mathrm{pA}(n=6)$ for voltage steps from -80 to $-10 \mathrm{mV}$. The current evoked by this voltage step inactivated slowly. The current decay of the mean inward current from five bipolar cells was well fit by single exponential curve with a time constant of $37.1 \mathrm{~ms}$. In contrast, inward TTX-sensitive currents were never observed in ON bipolar cells of which axon terminals ramified the innermost IPL $(n=8)$.

We obtained results similar to those with TTX when we substituted choline for extracellular sodium (Fig. $3 c, d$ ). Choline substitution reduced an inward current that was apparent when the current trace measured in choline was subtracted from the control current trace $(-20.2 \pm 2.9 \mathrm{pA})$ (Fig. $3 d$ ). We observed this effect of choline in recordings from three ON bipolar cells with axon terminals ramifying in the mid-IPL but not in recordings from two ON bipolar cells with axon terminals ramifying in the innermost IPL. The cholinesensitive inward current was smaller than the TTX-sensitive inward current. This may be attributed to the high concentrations of extracellular choline that have been reported to reduce voltage-gated potassium currents (Fatt and Katz, 1953; Schlatter et al., 1993; Delmas and Gola, 1995), which would cause an underestimation of the net inward current. Although the inward current was small, the choline substitution experiment is consistent with the notion that sodium currents exist in a subset of ON bipolar cells that enhance light-evoked voltage responses.

\section{Sodium currents activate and inactivate over the physiological membrane potential range}

To examine whether the sodium channels on bipolar cells have appropriate activation and inactivation ranges to boost their voltage responses, we measured the voltage dependence of activation and inactivation of the sodium channels on bipolar cells that had axon terminals ramifying in the mid-IPL. The mean inactivation range was obtained by plotting the peak amplitude of the TTXsensitive current in response to a test pulse to $-10 \mathrm{mV}$ as a function of conditioning steps to various prepulse voltages (Fig. $3 f$, closed circles). The voltage dependence of inactivation was well fit by the Boltzmann equation. The sodium current began to inactivate at potentials more positive than $-60 \mathrm{mV}$ and was fully 
inactivated at $-20 \mathrm{mV}$, with inactivation half complete at a holding potential of $-37.5 \mathrm{mV}(n=5)$. These data demonstrate that over the range of resting membrane potentials of bipolar cells from -40 to $-65 \mathrm{mV}$ (Awatramani and Slaughter, 2000; Euler and Masland, 2000), a significant fraction (59-98\%) of sodium channels was not inactivated and was available to boost the bipolar cell membrane potential (Fig. $3 f$, hatched area).

The average activation range from four bipolar cells was obtained by measuring the peak TTX-sensitive current in response to a series of positive voltage steps from a holding potential of $-80 \mathrm{mV}$ (Fig. $3 e$ ). The sodium current was activated at $-60 \mathrm{mV}$ and at more positive potentials (Fig. 3e). Sodium channel conductance was calculated from the currents by dividing by the driving force $\left(V-E_{\mathrm{Na}}\right)$ and plotted versus the membrane potential (Fig. 3f, open circles). The activation curve was well fit by the Boltzmann equation (Fig. $3 f$, solid line) with a maximum conductance of $0.84 \mathrm{nS}$ (normalized in Fig. $3 f$ ), a half-activating voltage of $-18.7 \mathrm{mV}$, and the Boltzmann constant of $10.1 \mathrm{mV}$.

We estimated the extent of L-EPSP enhancement in bipolar cells by voltagedependent sodium channels from the sodium current activation and inactivation curves. The average resting potential for seven transient $\mathrm{ON}$ bipolar cells was $-62 \pm$ $2.5 \mathrm{mV}$, which is in agreement with previous studies (Awatramani and Slaughter, 2000; Euler and Masland, 2000). At this membrane potential, we assumed that the inactivation of the sodium channel was negligible (Fig. $3 f$ ). Steady-state sodium currents were obtained from the following relationship: $I_{\mathrm{Na}}=g_{\mathrm{Na}}$ $\left(V-E_{\mathrm{Na}}\right)$, where $E_{\mathrm{Na}}$ is the equilibrium potential for the sodium ion $(+116 \mathrm{mV})$, and $g_{\mathrm{Na}}$ is the sodium channel conductance. These ON bipolar cells depolarized to $-54.3 \mathrm{mV}$ in response to light stimulation if sodium channels were not activated. At this membrane potential, a sodium conductance of $0.04 \mathrm{nS}$ was derived from the activation curve (Fig. $3 f$ ), indicating $6.52 \pm 2 \mathrm{pA}$ voltage-activated sodium current. The estimated enhancement of the bipolar cell voltage response by the sodium current is determined by the current magnitude and input resistance $(V=$ $\left.I_{(\mathrm{Na})} R_{\text {(input) }}\right)$. The average input resistance measured at $-60 \mathrm{mV}$ was $1.74 \pm 0.4 \mathrm{G} \Omega$. At the peak of the light response, the input resistance should be lower, attributable to the opening of mGluR6-gated channels. Assuming a light-evoked excitatory conductance of $0.63 \mathrm{nS}$, as reported for salamander transient ON cone bipolar cells (type 7) (Wu et al., 2000), the estimated input resistance at the peak of the L-EPSP would be $819 \mathrm{M} \Omega$. Over the range of input resistances from 1.74 to $0.819 \mathrm{G} \Omega$, the enhancement of the L-EPSP by the sodium current would range from 11 to $5.3 \mathrm{mV}$, assuming no inactivation of the sodium channels at $-54 \mathrm{mV}$. If sodium channel inactivation was complete at this membrane potential, then $\sim 10 \%$ of the channels would be unavailable, giving rise to slightly smaller enhancements of 9.9-4.8 $\mathrm{mV}$. These estimates are in good agreement with the actual mean enhancement of $7.1 \mathrm{mV}$ that we observed (Fig. 1a). This suggests that sodium channels on bipolar cells are capable of enhancing their L-EPSPs and consequently the excitatory synaptic input to ganglion cells.

\section{TTX reduced light-evoked EPSCs in a subset of ON-OFF ganglion cells}

To assess whether bipolar cell sodium channels contributed to retinal information processing, we determined whether they enhanced visual signals by recording light responses from ganglion cells. L-EPSCs from ganglion cells were isolated by voltage clamping at $E_{\mathrm{Cl}}(-59 \mathrm{mV})$. Strychnine was included in the bath to block the change-sensitive, surround, inhibitory inputs (Cook et al., 1998). We confined our analysis to the ON pathway, because OFF ganglion cell responses also are mediated by input from the ON pathway (Belgum et al., 1982; Arkin and Miller, 1988; Higgs et al., 2002).

TTX reduced the L-EPSCs at light onset in a specific morphological class of transient ON-OFF ganglion cells of which dendrites ramified in the mid-IPL ( $42.1 \pm 7.4 \%$ of control) (Fig. $4 a$ ). In contrast, TTX did not reduce the L-EPSCs recorded in ON ganglion cells, of which dendrites ramified the innermost IPL (123.3 $\pm 4 \%$ of control) (Fig. $4 b$ ) or in ON-OFF cells with bistratified dendrites ramifying at both the inner and outer borders of IPL (107 $\pm 9 \%$ of control) (Fig. $4 c)$. Instead, TTX enhanced the sustained L-EPSCs of ON ganglion cells (Fig. 4b), in agreement with previous studies (Cook and McReynolds, 1998; Flores-Herr et al., 2001). The enhancement observed in ON ganglion cells was attributed to the TTX blockade of inhibition from amacrine cells, as originally reported by Cook and McReynolds (1998), because the enhancement was not observed when the $\mathrm{GABA}_{\mathrm{A}}$ and $\mathrm{GABA}_{\mathrm{C}}$ receptor blockers bicuculline and picrotoxin were present in the bath $(101 \%$ of control; $n=2)$. Our results 


\section{a $Q X-314$}
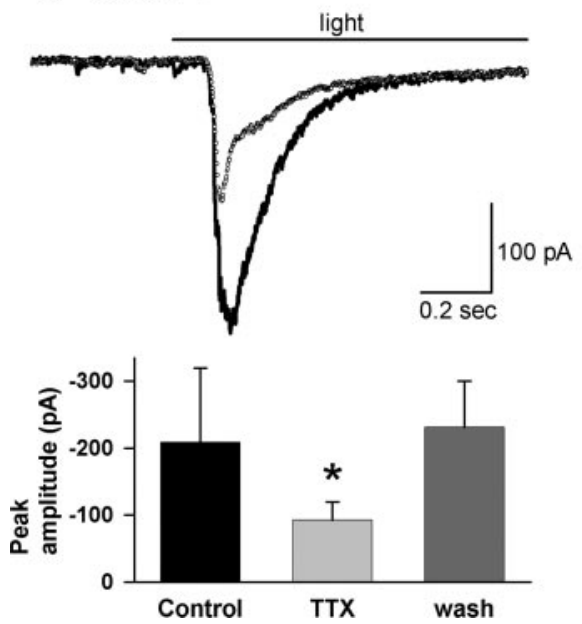

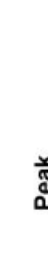

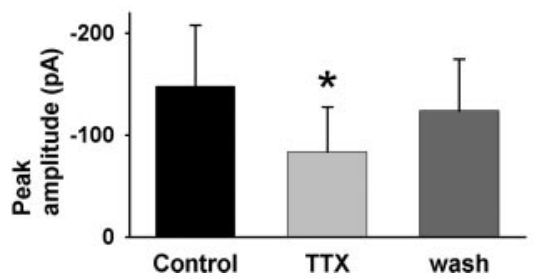

Figure 5. The reduction of L-EPSCs by TTX was not attributable to sodium channels on ganglion cells or amacrine cells. $\boldsymbol{a}$, L-EPSCs were recorded from transient ganglion cells with dendrites that ramified in the mid-IPL (solid trace, top). TTX (dotted trace) reduced the L-EPSCs even when QX-314 (5 mm) was included in the pipette to block sodium channels on the recorded ganglion cell. The bar graph summarizes the effects of TTX in the presence of QX-314 (control, $-208.7 \pm 111 \mathrm{pA} ;$ TTX, $-92.9 \pm$ $27 \mathrm{pA} ;{ }^{*} p<0.05 ; n=4$; bottom). $\boldsymbol{b}$, L-EPSCs were recorded from transient ganglion cells with dendrites that ramified in the mid-IPL (solid trace, top) after blocking sodium channel activity in the recorded ganglion cell with QX-314 (5 mm) and signaling from amacrine cells with strychnine $(5 \mu \mathrm{M})$, bicuculline $(200 \mu \mathrm{M})$, I4AA $(20 \mu \mathrm{M})$, picrotoxin $(200 \mu \mathrm{M}), \mathrm{SCH} 23390$ (10 $\mu \mathrm{m})$, sulpride (20 $\mu \mathrm{M})$, and D-tubocurarine (50 $\mu \mathrm{m})$. TTX (dotted trace) still reduced the EPSCs in the presence of these blockers. The bar graph summarizes the effects of TTX after blocking ganglion cell sodium channel activity and amacrine cell signaling (control, $-147.8 \pm$ $60 \mathrm{pA} ; \mathrm{TTX},-83.4 \pm 44 \mathrm{pA} ;{ }^{*} p<0.05 ; n=4$; bottom).

suggest that voltage-gated sodium channels are confined to the bipolar cells that provide input to a particular class of ON-OFF ganglion cell of which dendrites stratify in the mid-IPL.

\section{TTX reduced ganglion cell EPSCs by blocking bipolar cell sodium currents}

Although light-evoked EPSCs were recorded by the voltageclamp method, it was possible that sodium channels on ganglion cells could have contributed to the L-EPSC if there was inadequate space clamp. Given that the TTX reduced L-EPSCs in only one of three classes of ganglion cells, poor space clamping is an unlikely explanation for our observations. Nevertheless, to rule this out, we included QX-314 (5 mM) in the recording pipette to block sodium channels in the recorded ganglion cells. QX-314 eliminated the transient inward sodium current in response to positive voltage steps a few minutes after it diffused into the cell. As shown in Figure $5 a$, L-EPSCs were not reduced by QX-314 ( $p=0.40$ vs control) (Fig. $4 a$ ) for recording durations of up to 30 min, suggesting that TTX did not reduce L-EPSCs by blocking intrinsic sodium channels. The subsequent bath application of TTX reduced the L-EPSCs in these cells ( $46.7 \pm 4.9 \%$ of control; $n=4$ ), demonstrating that the L-EPSC suppression by TTX occurred at a site presynaptic to the ganglion cells.

Because many types of salamander amacrine cells use sodium spikes (Werblin, 1977; Cook and Werblin, 1994), they could contribute to the suppression of L-EPSCs in ganglion cells observed with TTX. To test for this possibility, we prevented amacrine cell signaling by pharmacologically blocking neurotransmitter receptors on their targets. We added strychnine, bicuculline, imidazole-4-acetic acid hydrochloride (I4AA), picrotoxin, $R(+)$ 7-chloro-8-hydroxy-3-methyl-1-phenyl-2,3,4,5,-tetrahydro-1H-3benzazepine hydrochloride (SCH23390), sulpride, and D-tubo-- curarine to the bath to block glycine, $\mathrm{GABA}_{\mathrm{A}}, \mathrm{GABA}_{\mathrm{C}}, \mathrm{D}_{1}, \mathrm{D}_{2}$, and nicotine receptors, respectively. QX-314 was also included in a recording pipette to block sodium channels in the recorded ganglion cell. Figure $5 b$ shows that, under these conditions, TTX still reduced light-evoked ON EPSCs in transient ON-OFF ganglion cells $(52.3 \pm 6.8 \%$ of control), indicating that sodium channels in a subset of ON bipolar cells enhanced LEPSCs in ganglion cells.

We tested the effects of TTX on 77 ganglion cells using different combinations of intracellular QX-314 and GABA, glycine, dopamine, and nicotinic receptor blockers. Regardless of the combination of receptor or channel blockers in the bath or pipette, TTX only reduced ( $\geq 30 \%$ reduction) the L-EPSCs of ON-OFF ganglion cells with dendrites that ramified in the mid-IPL $(n=57)$. In contrast, the L-EPSCs that were recorded in bistratified ON-OFF ganglion cells $(n=13)$ and in ON ganglion cells $(n=7)$ were not reduced by TTX.

\section{TTX-sensitive ganglion and bipolar cell} processes ramify in the mid-IPL

The mid-IPL colocalization of transient ON bipolar cell axon terminals and of ON-OFF ganglion cell dendrites suggested that these two classes of neurons made synaptic contacts. To analyze this further, we examined the stratification of processes from all of the bipolar cells and ganglion cells in the aforementioned experiments, as summarized in Figure 6. The stratifications of either bipolar cell axon terminals or ganglion cell dendrites were analyzed by measuring the depth of their stratification in the IPL. The stratification of each cell is represented by a dot or by dots connected with a line for multistratified processes. The axon terminals from TTX-sensitive ON bipolar cells stratified in the mid-IPL, with all processes found within layers $50-80 \%$ of the IPL depth (Fig. 6a). TTX-sensitive ganglion cells were either monostratified or multistratified (Fig. 6b). The main dendrites of these ganglion cells also ramified in the mid-IPL, with most processes located within layers $40-70 \%$ of the IPL depth. Some of these ganglion cells had additional minor processes, stratifying in the innermost or outermost IPL, that are represented by open circles.

In contrast, the axon terminal arbors for ON bipolar cells that were insensitive to sodium channel blockers stratified in distinct sublaminas from the TTX-sensitive bipolar cells (Fig. $6 c$ ). The axonal processes of these bipolar cells stratified at $80-100 \%$ of the IPL depth. Similarly, the dendritic processes of TTX-insensitive ganglion cells stratified in IPL sublaminas that were distinct from those in the TTX-sensitive ganglion cell sublaminas. There were no TTX-insensitive ganglion cell processes located at the 50-70\% depths where the TTX-sensitive processes were most numerous. The processes of TTX-insensitive ganglion cells were found in either the $0-20$ or $80-100 \%$ depths of the IPL (Fig. $6 d$ ).

Our data show that the processes from TTX-sensitive and -insensitive neurons stratify primarily in mutually exclusive regions of the IPL. In addition, we show that the processes of TTXsensitive bipolar and ganglion cells stratify in similar layers of the 
IPL, consistent with the notion that these two sets of neurons contact each other. Likewise, the processes of TTX-insensitive bipolar and ganglion cells overlap in the innermost IPL layers, suggesting that these sets of neurons contact each other.

Bipolar cell sodium channels change the light sensitivity and dynamic range of ON transient ganglion cells

We constructed intensity-response relationships for TTX-sensitive ON-OFF ganglion cells to determine how bipolar cell sodium channels affected visual information processing. The amplitudes of L-EPSCs evoked by small spots were plotted as a function of log intensity. Figure $7 a$ shows that TTX shifted the intensityresponse curve to brighter intensities, increasing the $L_{50}$ value (the light intensity that evoked a half-maximum response) and reducing the maximum response. The reduced maximum response amplitude suggested that bipolar cell sodium channels boost L-EPSC amplitudes in these $\mathrm{ON}-\mathrm{OFF}$ ganglion cells. The increased $L_{50}$ value, measured in the presence of TTX, suggested that regenerative sodium currents in bipolar cells enhance ganglion cell light sensitivity by boosting bipolar to ganglion cell transmission. TTX also increased the dynamic range and decreased the slope of the intensity-response relationship in TTX-sensitive ganglion cells. This suggests that bipolar cell sodium channels boost the gain of ganglion cell light responses and limit the dynamic range of light intensities to which they respond.

Are the intensity response functions for TTX-sensitive and -insensitive ganglion cells different? We compared the intensity-response curves from TTX-sensitive ganglion cells $(n=12$ transient $\mathrm{ON}$ responses and dendrites that stratified in the mid-IPL) and from TTX-insensitive ganglion cells ( $n=5$ either sustained ON ganglion cells or transient ONOff ganglion cells with bistratified dendrites), as shown in Figure $7 b$. The maximum amplitude and $L_{50}$ values of the TTXinsensitive ganglion cells were normalized to values obtained from TTX-sensitive ganglion cells. The maximum amplitude of the TTXinsensitive cells was smaller than the amplitude of the TTX-sensitive cells $(p<0.05)$. The TTX-insensitive ganglion cells were also less sensitive to light. Their $L_{50}$ value was shifted to brighter light intensities compared with the TTX-sensitive ganglion cells $(p<0.05)$. The dynamic ranges of the intensity-response curves for the two groups of ganglion cells were also different, as shown by comparing the scaled TTX-insensitive curve to the TTX-sensitive curve. The dynamic range of the TTX-sensitive ganglion cells was smaller than that in the TTX-insensitive cells $(1.47 \pm 0.2$ vs $2.87 \pm 0.3$ log intensity, respectively; $p<0.01$ ). Thus, the voltage-gated sodium channel found in a subset of bipolar cells shaped the light responses of TTXsensitive ganglion cells, indicating intensity-response functions that were distinct from those measured in TTX-insensitive ganglion cells.
Bipolar cells

a

:

b
Ganglion cells

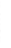

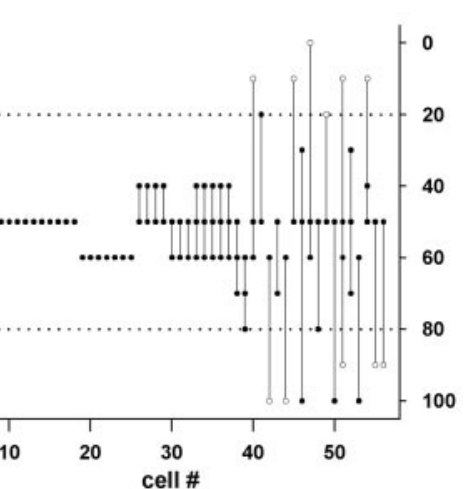

d
Figure 6. TTX-sensitive and -insensitive cells ramified in different sublaminas of the IPL. Ramification patterns of bipolar cell axon terminals or ganglion cell dendrites were plotted as a function of IPL depth, in which $0 \%$ is the inner nuclear layer border and near the mid-IPL (closed circles) $\boldsymbol{b}$, The main dendritic processes of TTX-sensitive ganglion cells were predominantly located in the cesses of TTX-insensitive ganglion cells, sustained $\mathrm{ON}$ ganglion cells (open circles), and bistratified ganglion cells (open triangles) were found in the innermost or outermost and innermost IPL, respectively.

\section{Discussion}

Sodium channels enhance light-evoked signaling in transient ON bipolar cells

TTX selectively reduced light responses in transient ON bipolar cells, suggesting that sodium channels were only present on this class of bipolar cells. This TTX effect was not attributable to its indirect actions on other neurons. TTX still reduced bipolar cell responses when amacrine and horizontal cell inputs were blocked. Photoreceptor inputs were not affected by TTX, suggesting that it acted directly on the transient ON bipolar cells. This notion was confirmed by our findings that TTX effects were eliminated after bipolar cell sodium channels were inactivated by membrane depolarization or blocked by intracellular QX-314. Our results show that voltage-gated sodium channels enhanced the light responses of transient, but not sustained, ON bipolar cells.

We extend the findings of Awatramani and Slaughter (2000) by demonstrating that light responses of transient ON bipolar cells were boosted by voltage-gated sodium currents. Sodium channels in transient bipolar cells enhanced the peak-tosustained response index, whereas the index of sustained bipolar cells was not affected by TTX, suggesting sodium channels selectively boosted the transient response component. Nawy (2000) 


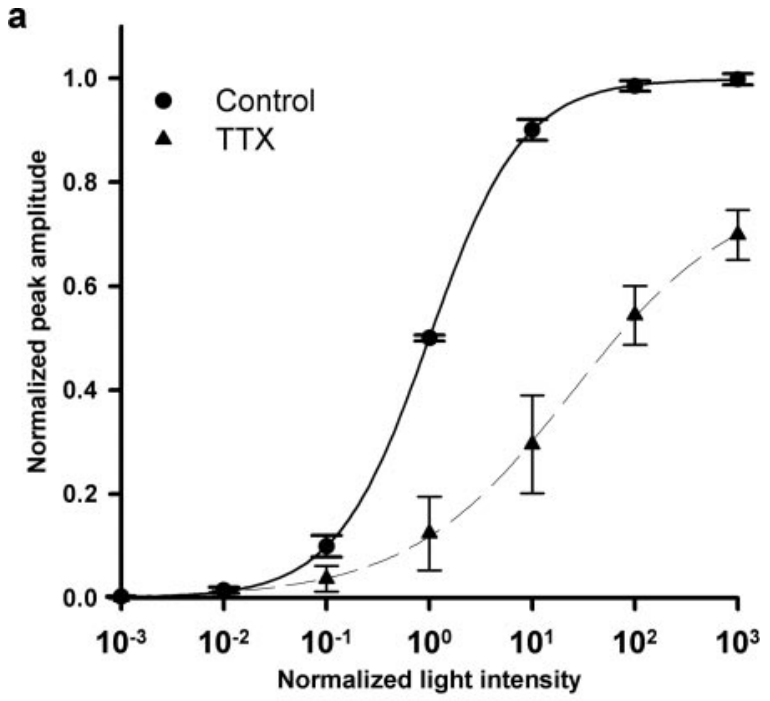

b

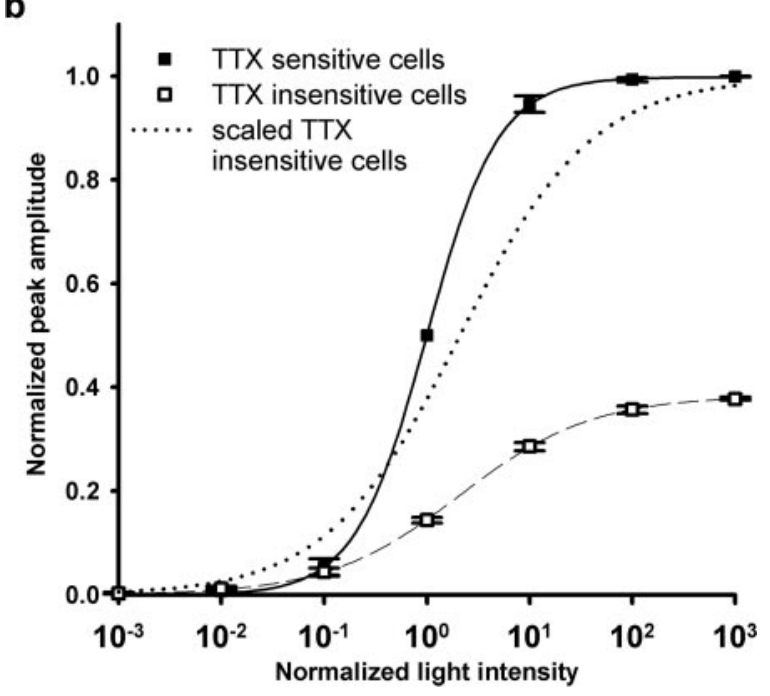

Figure 7. Bipolar cell sodium channels enhanced the light responsiveness in a subset of ganglion cells. $\boldsymbol{a}$, The light intensity-peak amplitude relationship was obtained from five $0 \mathrm{~N}$ OFF ganglion cells of which dendrites ramified in the mid-IPL (closed circles and thick line). Strychnine $(5 \mu \mathrm{m})$ was included in the bath solution. Curves are normalized to average values of maximum and $L_{50}$ in each cell. $\operatorname{TTX}(0.5 \mu \mathrm{m})$ shifted the curve to the right $\left(L_{50}=24.8 \pm 12 ; p<\right.$ $0.05)$ and reduced the maximum response $(0.79 \pm 0.05 \% ; p<0.01)$ (triangles and dotted line). The dynamic range was also increased by TTX (control, $2.0 \pm 0.2 ; \operatorname{TTX}, 2.62 \pm 0.2 ; p<$ $0.05)$. $\boldsymbol{b}$, The light intensity-response curves were obtained from 12 TTX-sensitive ganglion cells, of which dendrites ramified the mid-IPL, and from five TTX-insensitive ganglion cells, which is either $\mathrm{ON}$-sustained or ON-OFF bistratified. Curves are normalized to average values of maximum and $L_{50}$ in TTX-sensitive ganglion cells. In TTX-insensitive ganglion cells, the maximum response was smaller $(0.385 \pm 0.15 ; p<0.05)$. The normalized curve (dotted) shows that TTX-insensitive cells were less sensitive to light $\left(L_{50}=2.12 \pm 0.6 ; p<0.05\right)$ than TTXsensitive ganglion cells. The dynamic range was also wider in TTX-insensitive ganglion cells (TTX-sensitive cells, $1.47 \pm 0.2 ;$ TTX-insensitive cells, $2.87 \pm 0.3 ; p<0.01$ ).

and Shiells and Falk (1999) suggested that the calciumdependent desensitization of the mGluR6-gated channels shapes the transient response component of ON bipolar cells. Our observation that sodium currents shape transient responses is probably an independent mechanism, because BAPTA (10 mM), which was present in our intracellular solution, blocks calciumdependent desensitization (Nawy, 2000). Our TTX-sensitive, transient $\mathrm{ON}$ bipolar cells are similar to the cone-dominant, $\mathrm{ON}$ bipolar cells that ramify in the mid-IPL described by Wu et al. (2000). Results from dissociated goldfish and rat bipolar cells also suggested that sodium channels were expressed only in some cone bipolar cells (Pan and Hu, 2000; Zenisek et al., 2001). Our findings suggest that voltage-gated sodium channels amplify the transient responses of cone-dominant, ON bipolar cells.

Sodium channels boost bipolar to ganglion cell transmission TTX selectively reduced L-EPSCs in ON-OFF ganglion cells, of which dendrites ramified the mid-IPL. L-EPSCs of ON sustained and bistratified ON-OFF ganglion cells were not affected by TTX. The axon terminals of TTX-sensitive, ON transient bipolar cells ramified in the same IPL sublaminas as the TTX-sensitive ganglion cell dendrites (Fig. 6). In contrast, TTX-insensitive bipolar and ganglion cells ramified near the margins of the IPL. Our findings are in agreement with previous studies suggesting that the mid-IPL encodes transient responses, and the margins of the IPL encode more sustained responses (Wu et al., 2000; Roska and Werblin, 2001). Our results extend these findings by demonstrating that sodium channels boost transient $\mathrm{ON}$ signaling between bipolar and ganglion cells.

\section{Location of sodium channels on bipolar cells}

We found that TTX reduced light-elicited voltage responses and voltage-dependent current responses in some axotomized ON bipolar cells, suggesting that sodium channels were located on either the soma or the dendrites. This is in agreement with earlier observations in dissociated bipolar cells (Pan and Hu, 2000; Zenisek et al., 2001). We could label sodium channels in zebrafish bipolar cells with a polyclonal antibody used to detect sodium channels on goldfish bipolar cells (Zenisek et al., 2001). However, we were unsuccessful in labeling sodium channels in salamander retina with either polyclonal or monoclonal anti-sodium channel (III-IV loop) antibodies.

\section{Activation and inactivation properties of bipolar cell sodium currents}

The sodium currents we observed in transient $\mathrm{ON}$ bipolar cells had slower kinetics (Fig. 3) than that reported for amacrine cells or ganglion cells (Barnes and Werblin, 1986; Lukasiewicz and Werblin, 1988). The enhancement of the slow, light-evoked EPSCs in bipolar cells is consistent with these currents being persistent. Sustained sodium currents have been associated with dendrites rather than axons and are thought to enhance the efficacy of excitatory synaptic inputs in dendrites of cortical and hippocampal neurons (Stafstrom et al., 1985; Magee and Johnston, 1995; Stuart and Sakmann, 1995).

The sodium currents in the present study inactivated slowly and had relatively sustained time courses, which differs from the transient sodium current kinetics previously reported for dissociated bipolar cells (Pan and Hu, 2000; Zenisek et al., 2001). These differences may, in part, be attributable to the preparations used in the previous (enzymatically dissociated bipolar cells from rat or fish) and present studies (bipolar cells in dark-adapted slices from salamander). The molecular basis of transient and persistent sodium currents is unclear. Molecular analysis has not identified two separate subtypes of sodium channels that correspond to the different current kinetics observed (Ogata and Ohishi, 2002). It was proposed that two different types of sodium currents are generated by a uniform population of channels that can switch between different gating modes (Alzheimer et al., 1993). When we recorded bipolar cell sodium currents in light, they were more transient than in dark and more similar to the results from isolated bipolar cells (T. Ichinose and P. D. Lukasiewicz, unpublished observations). 
In many neurons, dendritic sodium channels are activated at more negative membrane potentials than axonal sodium channels. In rat sensorimotor cortex, the membrane potential for halfmaximum activation was $-50.4 \mathrm{mV}$ for dendritic sodium channels compared with $-43.5 \mathrm{mV}$ for axonal sodium currents (Brown et al., 1994). Because dendritic sodium channels can be activated at membrane potentials more negative than action potential threshold, they are well suited to amplify subthreshold EPSPs (Stuart and Sakmann, 1995). The half-activation membrane potential of bipolar cell sodium currents is more positive than for other CNS neurons (Fig. 3f) (Pan and Hu, 2000; Zenisek et al., 2001). These properties are well suited to boosting excitatory inputs to bipolar cells, because bipolar cells have more positive resting potentials $(-65$ to $-40 \mathrm{mV}$ ) than most CNS neurons, and they do not fire action potentials.

We have shown for the first time that bipolar cell sodium channels enhance visual signals and light sensitivity in specific classes of bipolar and ganglion cells. This is consistent with the notion that bipolar cell sodium channels are operational over a physiological range of bipolar cell membrane potentials (Fig. $3 f$, hatched area). We confirmed this by constructing inactivation and activation curves of the bipolar cell sodium channels (Fig. $3 f$ ). The activation and inactivation properties of voltage-gated sodium channels are appropriate for amplifying bipolar cell voltage responses, as demonstrated by the good agreement between the observed and estimated enhancements of bipolar cell voltage responses (see Results).

\section{Role of bipolar cell sodium channels in retinal processing} Bipolar cell sodium channels contribute to retinal processing. They enhanced bipolar cell L-EPSPs by amplifying the transient component of cone-dominant, ON bipolar cells, augmenting their responses to changes in illumination. Bipolar to ganglion cell signaling was also enhanced by bipolar cell sodium channels, boosting the transient ganglion cell responses to illumination. This class of ganglion cell was more sensitive to light than ganglion cells receiving input from TTX-insensitive bipolar cells. The higher light sensitivity is not attributable to rod input, because we show that these ganglion cells stratify in the mid-IPL where they receive input from cone-dominant bipolar cells (Wu et al., 2000), and we used red light stimuli, which primarily activates cones in salamander (Yang and $\mathrm{Wu}, 1997$ ). The dynamic range was also narrower for this class of ganglion cell, and their responses to increments of illumination were larger than ganglion cells receiving TTX-insensitive input. This is in agreement with previous studies that have shown that the dynamic range of transient ganglion cells is narrower than that of sustained ganglion cells (Werblin and Copenhagen, 1974; Thibos and Werblin, 1978). The dynamic range of bipolar and ganglion cell responses to light has been attributed to GABA-mediated input from amacrine cells (Euler and Masland, 2000; Ichinose and Lukasiewicz, 2002). Our results indicate that sodium channels in bipolar cells also affect the sensitivity and gain of ganglion cell responses to light. Bipolar cell sodium channels enhanced the light sensitivity, the maximum amplitude, and shortened the dynamic range for transient, but not sustained, ON ganglion cell responses. Our results suggest that bipolar cell sodium channels enhance transient signaling in the $\mathrm{ON}$ pathway and contribute to the temporal segregation of retinal signals.

\section{References}

Alzheimer C, Schwindt PC, Crill WE (1993) Modal gating of $\mathrm{Na}^{+}$channels as a mechanism of persistent $\mathrm{Na}^{+}$current in pyramidal neurons from rat and cat sensorimotor cortex. J Neurosci 13:660-673.
Arkin MS, Miller RF (1988) Bipolar origin of synaptic inputs to sustained OFFganglion cells in the mudpuppy retina. J Neurophysiol 60:1122-1142.

Awatramani GB, Slaughter MM (2000) Origin of transient and sustained responses in ganglion cells of the retina. J Neurosci 20:7087-7095.

Barnes S, Werblin F (1986) Gated currents generate single spike activity in amacrine cells of the tiger salamander retina. Proc Natl Acad Sci USA 83:1509-1512.

Belgum JH, Dvorak DR, McReynolds JS (1982) Light-evoked sustained inhibition in mudpuppy retinal ganglion cells. Vision Res 22:257-260.

Brown AM, Schwindt PC, Crill WE (1994) Different voltage dependence of transient and persistent $\mathrm{Na}^{+}$currents is compatible with modal-gating hypothesis for sodium channels. J Neurophysiol 71:2562-2565.

Cook PB, McReynolds JS (1998) Lateral inhibition in the inner retina is important for spatial tuning of ganglion cells. Nat Neurosci $1: 714-719$.

Cook PB, Werblin FS (1994) Spike initiation and propagation in wide field transient amacrine cells of the salamander retina. J Neurosci 14:3852-3861.

Cook PB, Lukasiewicz PD, McReynolds JS (1998) Action potentials are required for the lateral transmission of glycinergic transient inhibition in the amphibian retina. J Neurosci 18:2301-2308.

Delmas P, Gola M (1995) Choline blocks large conductance KCa channels in mammalian sympathetic neurones. Neurosci Lett 189:109-112.

Euler T, Masland RH (2000) Light-evoked responses of bipolar cells in mammalian retina. J Neurophysiol 83:1817-1829.

Fatt P, Katz B (1953) The electrical properties of crustacean muscle fibres. J Physiol (Lond) 120:171-204.

Flores-Herr N, Protti DA, Wassle H (2001) Synaptic currents generating the inhibitory surround of ganglion cells in the mammalian retina. J Neurosci 21:4852-4863

Gonzalez-Burgos G, Barrionuevo G (2001) Voltage-gated sodium channels shape subthreshold EPSPs in layer 5 pyramidal neurons from rat prefrontal cortex. J Neurophysiol 86:1671-1684.

Higgs MH, Romano C, Lukasiewicz PD (2002) Presynaptic effects of group III metabotropic glutamate receptors on excitatory synaptic transmission in the retina. Neuroscience 115:163-172.

Ichinose T, Lukasiewicz PD (2002) GABA transporters regulate inhibition in the retina by limiting $\mathrm{GABA}_{\mathrm{C}}$ receptor activation. J Neurosci 22:3285-3292.

Lukasiewicz P, Werblin F (1988) A slowly inactivating potassium current truncates spike activity in ganglion cells of the tiger salamander retina. J Neurosci 8:4470-4481.

Lukasiewicz PD, Maple BR, Werblin FS (1994) A novel GABA receptor on bipolar cell terminals in the tiger salamander retina. J Neurosci 14:1202-1212.

Magee JC, Johnston D (1995) Synaptic activation of voltage-gated channels in the dendrites of hippocampal pyramidal neurons. Science 268:301-304.

Nawy S (2000) Regulation of the on bipolar cell mGluR6 pathway by $\mathrm{Ca}^{2+}$. J Neurosci 20:4471-4479.

Nelson R, Famiglietti Jr EV, Kolb H (1978) Intracellular staining reveals different levels of stratification for on- and off-center ganglion cells in cat retina. J Neurophysiol 41:472-483.

Ogata N, Ohishi Y (2002) Molecular diversity of structure and function of the voltage-gated $\mathrm{Na}^{+}$channels. Jpn J Pharmacol 88:365-377.

Pan Z-H, Hu H-J (2000) Voltage-dependent $\mathrm{Na}^{+}$currents in mammalian retinal cone bipolar cells. J Neurophysiol 84:2564-2571.

Roska B, Werblin F (2001) Vertical interactions across ten parallel, stacked representations in the mammalian retina. Nature 410:583-587.

Schlatter E, Bleich M, Hirsch J, Markstahler U, Frobe U, Greger R (1993) Cation specificity and pharmacological properties of the $\mathrm{Ca}(2+)$ dependent $\mathrm{K}^{+}$channel of rat cortical collecting ducts. Pflügers Arch 422:481-491

Schwindt PC, Crill WE (1995) Amplification of synaptic current by persistent sodium conductance in apical dendrite of neocortical neurons. J Neurophysiol 74:2220-2224.

Shields CR, Lukasiewicz PD (2003) Spike-dependent GABA inputs to bipolar cell axon terminals contribute to lateral inhibition of retinal ganglion cells. J Neurophysiol 89:2449-2458.

Shiells RA, Falk G (1999) A rise in intracellular $\mathrm{Ca}^{2+}$ underlies light adaptation in dogfish retinal "on" bipolar cells. J Physiol (Lond) 514:343-350.

Stafstrom CE, Schwindt PC, Chubb MC, Crill WE (1985) Properties of persistent sodium conductance and calcium conductance of layer 
Vneurons from cat sensorimotor cortex in vitro. J Neurophysiol 53:153-170.

Stuart G, Sakmann B (1995) Amplification of EPSPs by axosomatic sodium channels in neocortical pyramidal neurons. Neuron 15:1065-1076.

Stuart GJ, Sakmann B (1994) Active propagation of somatic action potentials into neocortical pyramidal cell dendrites. Nature 367:69-72.

Thibos LN, Werblin FS (1978) The response properties of the steady antagonistic surround in the mudpuppy retina. J Physiol (Lond) 278:79-99.

Werblin FS (1977) Regenerative amacrine cell depolarization and formation of on-off ganglion cell response. J Physiol (Lond) 264:767-785.

Werblin FS, Copenhagen DR (1974) Control of retinal sensitivity: III lateral interactions at the inner plexiform layer. J Gen Physiol 63:88-110.
Werblin FS, Dowling JE (1969) Organization of the retina of mudpuppy, Necuturus maculosis. II. Intracellular recording. J Neurophysiol 32: $339-355$.

Wu SM, Gao F, Maple BR (2000) Functional architecture of synapses in the inner retina: segregation of visual signals by stratification of bipolar cell axon terminals. J Neurosci 20:4462-4470.

Yang X, Wu SM (1997) Response sensitivity and voltage gain of the rod- and cone-bipolar cell synapses in dark-adapted tiger salamander retina. J Neurophysiol 78:2662-2673.

Zenisek D, Henry D, Studholm K, Yazulla S, Matthews G (2001) Voltagedependent sodium channels are expressed in nonspiking retinal bipolar cells. J Neurosci 21:4543-4550. 